\title{
Post-operative radiotherapy is beneficial for T1/T2 triple negative breast cancer patients with four or more positive lymph nodes
}

\author{
Lin Chen ${ }^{1, *}$, Jinfeng Zhang ${ }^{2, *}$, Jiayi Chen ${ }^{3}$, Lili Liu ${ }^{1}$, Lili Liang ${ }^{1}$, Zhiyi Shangguan ${ }^{1}$ \\ and Dandan Wang ${ }^{1}$ \\ ${ }^{1}$ Department of Radiation Therapy Technology Center, Harbin Medical University Cancer Hospital, Harbin, China \\ ${ }^{2}$ Department of Breast Surgery, Harbin Medical University Cancer Hospital, Harbin, China \\ ${ }^{3}$ Department of Radiological Physics, Harbin Medical University Cancer Hospital, Harbin, China \\ * These authors have contributed equally to this work
}

Correspondence to: Dandan Wang, email: 407745429@qq.com

Keywords: triple negative breast cancer, adjuvant radiotherapy, positive nodes, survival

Received: July 10,2016 Accepted: March 27, $2017 \quad$ Published: April 18, 2017

Copyright: Chen et al. This is an open-access article distributed under the terms of the Creative Commons Attribution License 3.0 (CC BY 3.0), which permits unrestricted use, distribution, and reproduction in any medium, provided the original author and source are credited.

\section{ABSTRACT}

The efficacy of adjuvant radiotherapy for the treatment of triple negative breast cancer patients with varying numbers of positive lymph nodes is not clear. We assessed the association between adjuvant radiotherapy and survival in 943 T1/T2 triple negative breast cancer patients treated at our institute between 2008 and 2012. We determined that post-operative radiotherapy improved overall survival (OS), disease-free survival (DFS), and local recurrence-free survival (LRFS) in patients with $\geq 4$ positive nodes $(p=0.037, p=0.035$, and $p=0.012$, respectively $)$. Although Cox regression analysis demonstrated that radiotherapy was a significant prognostic factor in triple negative breast cancer with $\geq 4$ positive nodes, post-operative radiotherapy had no clear effect on OS, DFS, or LRFS in patients with 1-3 positive nodes $(p=0.849$, $p=0.860$, and $p=0.162$, respectively). The prognosis (i.e., OS, DFS, and LRFS) of triple negative breast cancer patients without lymph node metastasis who underwent breast-conserving surgery and post-operative radiotherapy was similar to that of patients who underwent mastectomy alone $(p=0.336, p=0.537$, and $p=0.978$, respectively). Our findings demonstrate that post-operative radiotherapy is beneficial for T1/T2 triple negative breast cancer patients with $\geq 4$ positive lymph nodes.

\section{INTRODUCTION}

Breast cancer is the most common malignant tumor that occurs in women worldwide and it is a leading cause of cancer-related deaths. There were an estimated 231,840 new cases in the United States in 2015 [1]. Breast cancer is classified based on three molecular markers: the estrogen receptor (ER), progesterone receptor (PR), and human epidermal growth factor receptor 2 (HER2). It is further classified into distinct subtypes: luminal A, luminal B, HER2, and triple negative [2-6]. Triple negative breast cancer (ER-, PR-, and HER2-negative) is associated with an increased risk of early metastasis and local recurrence relative to the other breast cancer subtypes [7]. Chemotherapy is the primary method of treatment of triple negative breast cancer patients, and the potential benefits of adjuvant radiotherapy are not yet clear [8]. Treatment of breast cancer patients is therefore challenging given the lack of treatment options.

Several studies have shown that radiotherapy can reduce the rate of loco-regional recurrence and prolong survival in breast cancer patients $[9,10]$. Radiotherapy reduced the overall death rate at 15 years by $3.8 \%(25.2 \%$ to $21.4 \%$ ) in patients who underwent breast-conserving surgery [11]. Adjuvant radiotherapy following breastconserving surgery was more effective than mastectomy alone [12]. However, the effectiveness of post-mastectomy radiotherapy in patients with 1-3 positive lymph nodes is still controversial. Some studies have shown that postmastectomy radiotherapy is beneficial for patients with 
1-3 positive nodes [10, 13-15]. However, McBride et al. reported that patients with $1-3$ positive nodes without risk features had a low rate of loco-regional recurrence, even without radiotherapy [16]. The $13^{\text {th }}$ St. Gallen International Breast Cancer Conference (2013) Expert Panel supported less extensive axillary treatment and shorter durations of radiation therapy for early breast cancer patients [17].

Post-mastectomy radiotherapy in patients with stage I-II triple negative breast cancer was associated with a $13.7 \%$ reduction in loco-regional recurrence and an $11.7 \%$ increase in overall survival (OS) in a large multicenter randomized trial from China [18]. A large retrospective cohort study found that the patients who were treated with breast-conserving surgery and radiotherapy had longer local recurrence-free survival (LRFS) compared to T1-2/N0 triple negative breast cancer patients who underwent mastectomy alone [12]. However, these results were not consistent with those of other studies [19-22]. Adjuvant radiotherapy was less beneficial for triple negative breast cancer patients who underwent breast-conserving surgery and radiotherapy compared to those who underwent mastectomy alone.

Heilongjiang Province is located in the northeast region of China. Breast cancer patients in this region typically undergo mastectomy rather than breastconserving surgery. Thus, adjuvant radiotherapy following mastectomy could be particularly beneficial to triple negative breast cancer patients in this province. In this study, we evaluated the impact of adjuvant radiotherapy on the survival of triple negative breast cancer patients with $1-3$, or $\geq 4$ positive lymph nodes and suggest revised criteria for adjuvant radiotherapy in triple negative breast cancer.

\section{RESULTS}

We identified 1,131 triple negative breast cancer patients (ER-, PR-, and HER2-negative) who were treated at our institute between 2008 and 2012. Patients who presented with metastases at the time of diagnosis $(29 ; 2.56 \%)$, not received chemotherapy $(26 ; 2.30 \%)$, had a tumor size $>5$ $\mathrm{cm}(5 ; 0.44 \%)$, were lost to follow-up $(57 ; 5.04 \%)$, received neo-adjuvant chemotherapy $(18 ; 1.59 \%)$, had no medical data available $(32 ; 2.83 \%)$, deficiency of data $(20: 1.77 \%)$, or who underwent breast-conserving surgery without radiotherapy $(1 ; 0.09 \%)$ were excluded from the study. We analyzed the remaining 943 triple negative breast cancer patients. The distribution of patients is shown in Figure 1.

The characteristics of the patients are shown in Table 1. Of the 943 patients, 295 (31.3\%) were $\leq 45$ and $648(68.7 \%)$ were $>45$ years of age. There were 417 $(44.2 \%)$ and $526(55.8 \%)$ patients who presented with a tumor size $\leq 2 \mathrm{~cm}$ and $2 \mathrm{~cm}<\mathrm{T} \leq 5 \mathrm{~cm}$, respectively. There were $504(53.5 \%)$ patients who presented with axillary node negative disease, 237 (25.1\%) with 1-3 positive lymph nodes, and $202(21.4 \%)$ with $\geq 4$ lymph node metastases. There were $256(27.1 \%)$ patients who

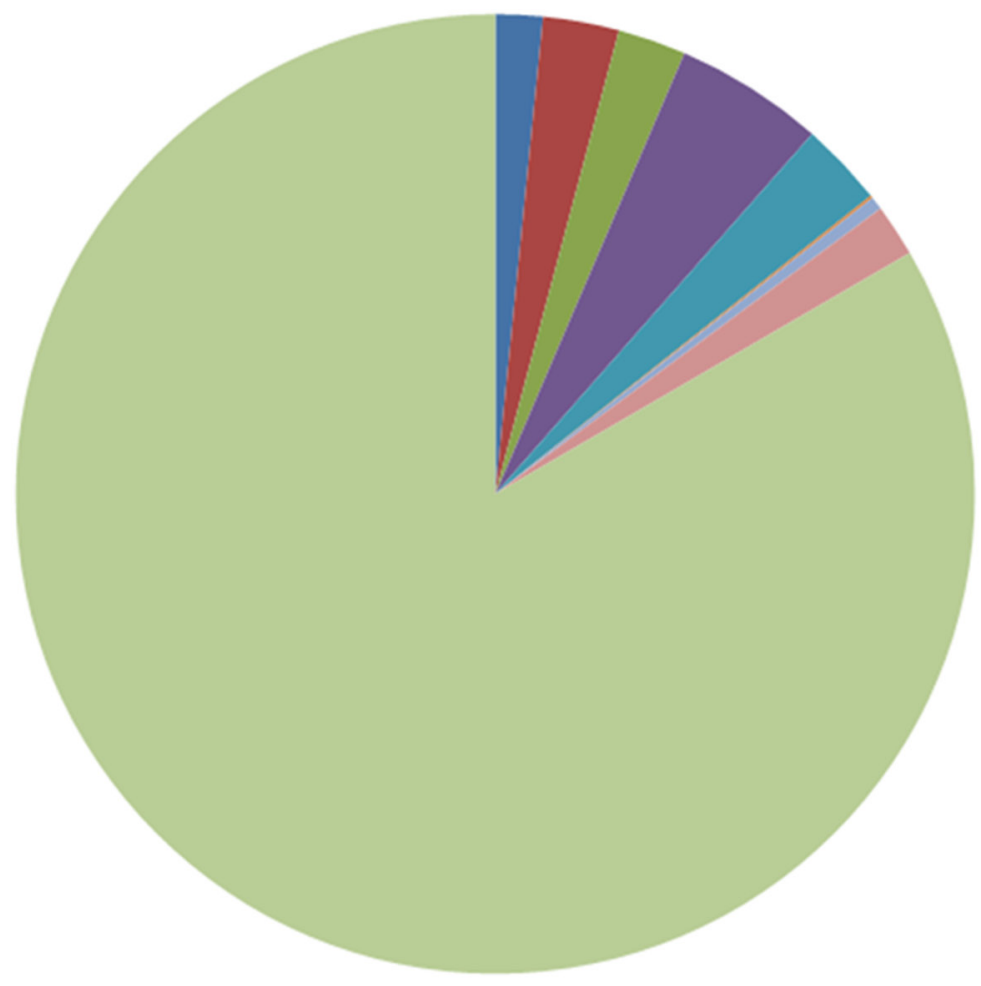

neoadjuvant chemotherapy $1.59 \%$

metastases at diagnosis $2.56 \%$

no chemotherapy $2.30 \%$

loss to follow-up $5.04 \%$

no medical data available $2.83 \%$

breast-conserving the rapy without radiotherapy $0.09 \%$

$\mathrm{T}>5 \mathrm{~cm} 0.44 \%$

deficiency of data $1.77 \%$

with analysis $83.38 \%$

Figure 1: Distribution triple negative breast cancer patients. 
Table 1: Characteristics of 943 patients with triple negative breast cancer between 2008 and 2012

\begin{tabular}{|c|c|c|c|c|c|}
\hline \multirow{2}{*}{ Characteristics } & \multirow{2}{*}{ Total patients } & \multicolumn{3}{|c|}{ Lymph node status } & \multirow{2}{*}{$p$-value } \\
\hline & & $\ln 0$ & $\ln 1-3$ & $\ln \geq 4$ & \\
\hline & $943, n(\%)$ & $504(53.5)$ & $237(25.1)$ & $202(21.4)$ & \\
\hline \multicolumn{6}{|l|}{ Age(years) } \\
\hline$\leq 45$ & $295(31.3)$ & 149 & 85 & 61 & 0.21 \\
\hline$>45$ & $648(68.7)$ & 355 & 152 & 141 & \\
\hline \multicolumn{6}{|l|}{ Tumor size } \\
\hline $\mathrm{T} \leq 2 \mathrm{~cm}$ & $417(44.2)$ & 299 & 72 & 46 & $<0.0001$ \\
\hline $2 \mathrm{~cm}<\mathrm{T} \leq 5 \mathrm{~cm}$ & $526(55.8)$ & 205 & 165 & 156 & \\
\hline \multicolumn{6}{|l|}{ Ki67 } \\
\hline$<14 \%$ & $256(27.1)$ & 132 & 58 & 66 & 0.122 \\
\hline$\geq 14 \%$ & $687(72.9)$ & 372 & 179 & 136 & \\
\hline \multicolumn{6}{|l|}{ p53 } \\
\hline positive & $581(61.6)$ & 320 & 136 & 125 & 0.279 \\
\hline negative & $362(36.4)$ & 184 & 101 & 77 & \\
\hline \multicolumn{6}{|l|}{ Histological grade } \\
\hline $\mathrm{G} 1-\mathrm{G} 2$ & $785(83.2)$ & 448 & 203 & 134 & $<0.0001$ \\
\hline G3 & $158(16.8)$ & 56 & 34 & 68 & \\
\hline \multicolumn{6}{|l|}{$\begin{array}{l}\text { Post-operative } \\
\text { radiotherapy }\end{array}$} \\
\hline Yes & $191(20.3)$ & 38 & 39 & 114 & $<0.0001$ \\
\hline No & $752(79.7)$ & 466 & 198 & 88 & \\
\hline \multicolumn{6}{|l|}{ Surgery } \\
\hline $\begin{array}{l}\text { Breast-conserving } \\
\text { surgery }\end{array}$ & $38(4.0)$ & 38 & $*$ & * & - \\
\hline Mastectomy & $905(96.0)$ & 466 & 237 & 202 & \\
\hline \multicolumn{6}{|l|}{ Chemotherapy } \\
\hline Yes & 943 & 504 & 237 & 202 & - \\
\hline No & $*$ & $*$ & $*$ & $*$ & \\
\hline
\end{tabular}

*the patients who were not conform to the criteria or too few were excluded.

presented with Ki67 index values $<14 \%$ and $687(72.9 \%)$ with values $\geq 14 \%$. Finally, there were $581(61.6 \%)$ P53-positive and 362 (36.4\%) P53-negative patients. All patients were treated with surgery and chemotherapy. There were $38(4.0 \%)$ patients who underwent breastconserving surgery and $905(96.0 \%)$ who underwent mastectomy. We also analyzed the relationship between the number of positive lymph nodes and various clinicopathological features of breast cancer patients. We found that the number of positive lymph nodes was correlated with tumor size $(p<0.0001)$ and histological grade $(p<0.0001)$. The choice of radiotherapy was primarily determined by the number of positive lymph nodes $(p<0.0001)$ (Table 1$)$.

A total of 191/943 (20.3\%) patients underwent postoperative radiotherapy. The median duration of followup was 53 months (range 4-78 months). The number of patients who had events (e.g., death, any recurrence, local regional recurrences) in different lymph nodes listed in Table 2 . Of the 202 patients with $\geq 4$ positive lymph nodes, 114 received post-mastectomy radiotherapy. All patients with $\geq 4$ positive lymph nodes underwent mastectomy. Kaplan-Meier survival curves were generated to evaluate the effects of post-mastectomy radiotherapy on OS, DFS, 
Table 2: Patients who had events (Death, Any recurrence, Local regional recurrences) in different lymph nodes

\begin{tabular}{lccccc}
\hline \multirow{2}{*}{ Lymph node status } & Total patients & $\begin{array}{c}\text { Post-operative } \\
\text { radiotherapy }\end{array}$ & Death & Any recurrence & $\begin{array}{c}\text { Local regional } \\
\text { recurrences }\end{array}$ \\
\cline { 2 - 6 } & $\mathbf{9 4 3}$ & & & $\mathbf{n}(\%)$ & \\
\hline $\ln \geq 4$ & 114 & Yes & $32(28.07)$ & $40(35.09)$ & $16(14.04)$ \\
& 88 & No & $37(42.05)$ & $43(48.86)$ & $24(27.27)$ \\
$\ln 1-3$ & 39 & Yes & $6(15.38)$ & $9(23.07)$ & $3(7.7)$ \\
& 198 & No & $32(16.16)$ & $44(22.22)$ & $32(16.16)$ \\
$\ln 0$ & 38 & Yes & $3(7.89)$ & $4(10.52)$ & $1(2.63)$ \\
& 466 & No & $61(13.09)$ & $65(13.94)$ & $12(2.58)$ \\
\hline
\end{tabular}

and LRFS. Importantly, post-mastectomy radiotherapy improved OS, DFS, and LRFS in triple negative breast cancer patients $(p=0.035, p=0.037$, and $p=0.012$, respectively, Figure 2a, 2b, 2c).

Univariate and multivariate survival analyses were performed to evaluate the impact of radiotherapy and clinicopathological factors (e.g., age, tumor size, histological grade, Ki67 index, and P53 status) on the prognosis of triple negative breast cancer patients with $\geq 4$ positive lymph nodes. Univariate Cox regression analysis indicated that tumor size $(p=0.034)$ and post-mastectomy radiotherapy $(p=0.04)$ were significant predictors of prognosis. Multivariate Cox regression analysis of OS demonstrated that tumor size $(p=0.032)$ and postmastectomy radiotherapy $(p=0.036)$ were significant prognostic factors (Table 3 ). The results of the univariate and multivariate Cox regression analysis of DFS and LRFS were similar to those of OS (Supplementary Table 1 and 2).

Of the 237 patients with 1-3 positive lymph nodes, 39 underwent post-mastectomy radiotherapy. There were few triple negative breast cancer patients with 1-3 positive lymph nodes who underwent breast-conserving surgery. Therefore, all of the patients we selected with 1-3 positive lymph nodes underwent mastectomy. We analyzed the impact of post-mastectomy radiotherapy on OS, DFS, and
LRFS using Kaplan-Meier survival curves. These data indicated post-mastectomy radiotherapy did not impact OS, DFS, and LRFS in triple negative breast cancer patients with $1-3$ positive nodes $(p=0.849, p=0.860$, and $p=0.162$, respectively, Figure $3 \mathrm{a}, 3 \mathrm{~b}, 3 \mathrm{c}$ ).

Of the 504 patients with negative nodes, 38 were treated with breast-conserving surgery and post-operative radiotherapy and 466 with mastectomy alone. The prognosis of triple negative breast cancer patients (OS, DFS, and LRFS) without lymph node metastasis who underwent breast-conserving surgery and post-operative radiotherapy was similar to that of patients who were treated with mastectomy alone $(p=0.336, p=0.537$, and $p=0.978$, respectively, Figure $4 \mathrm{a}, 4 \mathrm{~b}, 4 \mathrm{c})$. Our results indicate that patients treated with breast-conserving surgery and post-operative radiotherapy achieved an equivalent prognosis to patients treated with mastectomy alone.

\section{DISCUSSION}

Population-based studies have demonstrated that triple negative breast cancer patients have an increased risk of early metastasis and local recurrence compared to patients with other subtypes of breast cancer [23].
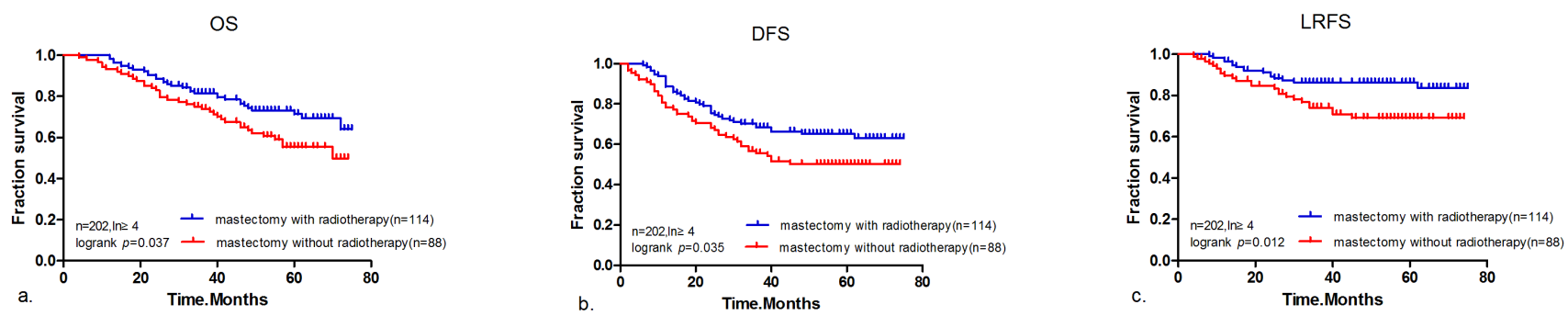

Figure 2: Kaplan-Meier analysis showing (a) OS, (b) DFS, and (c) LRFS for T1/T2 triple negative breast cancer patients with $\geq 4$ positive lymph nodes who were treated with mastectomy without radiotherapy $(n=88)$ or mastectomy with radiotherapy $(n=114)$. 
Table 3: Prognostic factors of OS in triple negative breast cancer patients with $\geq 4$ positive lymph nodes using the Cox proportional hazards model

\begin{tabular}{lcccc}
\hline Variables & $\begin{array}{c}\text { Hazard Ratio (Univariate } \\
\mathbf{9 5 \%} \mathbf{C I})\end{array}$ & $\boldsymbol{p}$-value & $\begin{array}{c}\text { Hazard Ratio (Multivariate } \\
\mathbf{9 5 \%} \mathbf{C I})\end{array}$ & $\boldsymbol{p}$-value \\
\hline $\begin{array}{l}\text { Age (years) } \\
\geq 45 \text { vs. }<45\end{array}$ & $1.394(0.797-2.439)$ & 0.244 & & \\
$\begin{array}{l}\text { Tumor size } \\
\geq 2 \mathrm{~cm} \text { vs. }<2 \mathrm{~cm}\end{array}$ & $2.064(1.055-4.037)$ & 0.034 & $2.087(1.067-4.083)$ & 0.032 \\
$\begin{array}{l}\text { Histological grade } \\
\text { G1-2 vs. G3 }\end{array}$ & $0.887(0.492-1.597)$ & 0.689 & & \\
$\begin{array}{l}\text { Ki67 status } \\
\geq 14 \% \text { vs.<14\% }\end{array}$ & $1.006(0.610-1.660)$ & 0.98 & & \\
$\begin{array}{l}\text { P53 status } \\
\text { Positive vs. Negative }\end{array}$ & $1.138(0.699-1.852)$ & 0.603 & & \\
$\begin{array}{l}\text { Post-mastectomy } \\
\text { radiotherapy } \\
\text { Yes vs. No }\end{array}$ & & & \\
\hline
\end{tabular}
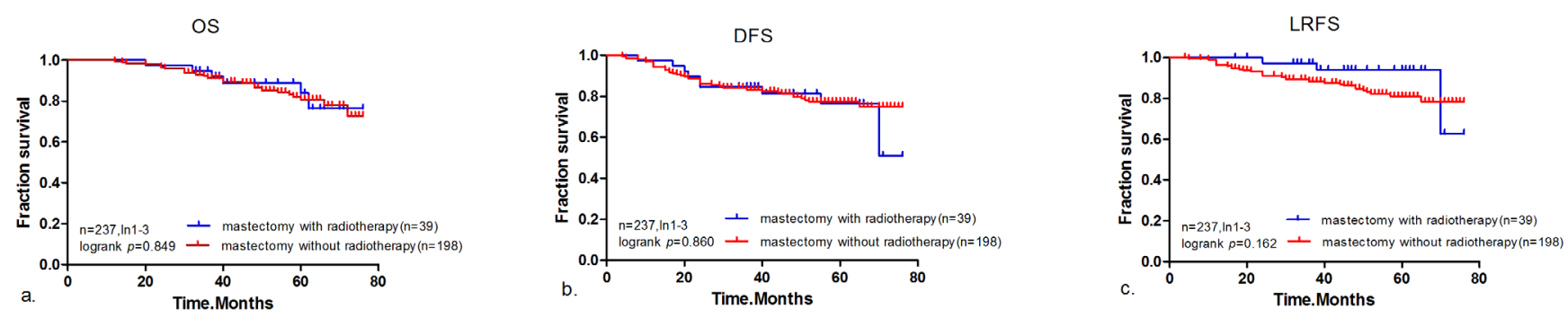

Figure 3: Kaplan-Meier analysis showing (a) OS, (b) DFS, and (c) LRFS for patients with triple negative breast cancer T1/T2 triple negative breast cancer patients with 1-3 positive lymph nodes who were treated with mastectomy without radiotherapy $(\mathrm{n}=198)$ or mastectomy with radiotherapy $(\mathrm{n}=39)$.
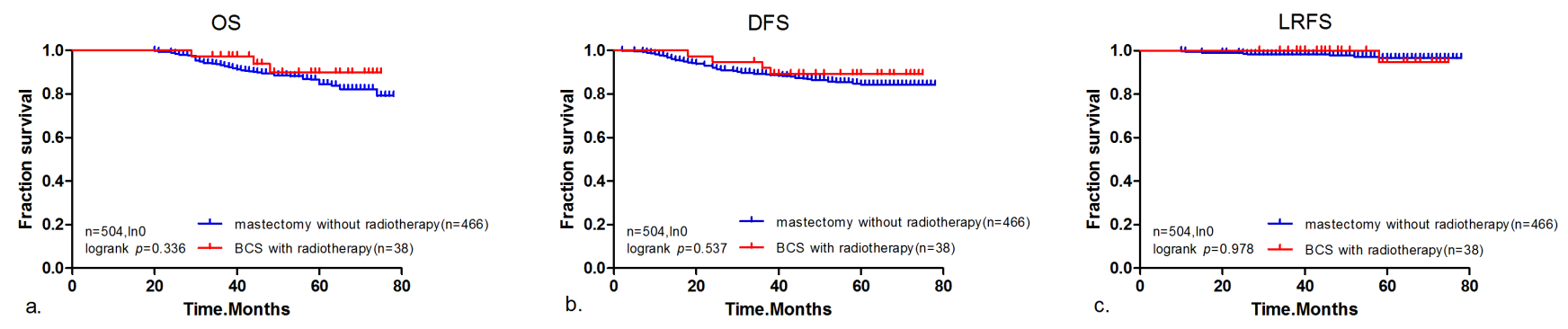

Figure 4: Kaplan-Meier analysis showing (a) OS, (b) DFS, and (c) LRFS for patients with T1/T2 triple negative breast cancer patients with no positive lymph nodes who were treated with breast-conserving surgery with post-operative radiotherapy $(\mathrm{n}=38)$ or mastectomy alone $(\mathrm{n}=466)$. 
There are several conflicting reports regarding the value of post-mastectomy radiotherapy for the treatment of triple negative breast cancer. Data from the Early Breast Cancer Trialists' Collaborative Group [10, 11] indicated that radiotherapy could improve survival. A prospective, randomized controlled multi-center trial in China also demonstrated that post-mastectomy radiotherapy significantly improved LRFS and OS in women with stage I and II triple negative breast cancer compared to mastectomy alone [18]. However, a Canadian study showed that breast-conserving surgery in combination with post-operative radiotherapy improved LRFS in patients with T1-2/N0 triple negative breast cancer compared to mastectomy alone, but did not significantly impact OS [12].

Data from the Danish Breast Cancer Cooperative Group $82 \mathrm{~b}$ and $82 \mathrm{c}$ trials indicated post-mastectomy radiotherapy was not beneficial for triple negative breast cancer patients who had positive lymph nodes and/ or T3-4 tumors [24]. However, these findings were not confirmed by other studies [19-22]. A population-based study from Sahlgrenska University Hospital reported that post-operative radiotherapy had no impact on the survival of patients from two similar regions of Sweden who were managed similarly. However, they did find that radiotherapy was indicated for patients with 1-3 positive nodes [25]. Finally, McBride et al. reported that patients with 1-3 positive nodes without risk features had a low rate of local recurrence, even in the absence of radiotherapy [16].

In this study, the primary outcome was relative survival. We analyzed differences in survival among triple negative breast cancer patients with either 1-3 or $\geq 4$ positive nodes who were treated with similar surgical procedures and adjuvant chemotherapy with the exception of post-mastectomy radiotherapy All patients received adjuvant therapy. Therefore, the relative effects of minor differences in chemotherapeutics were not significant.

Post-mastectomy radiotherapy improved OS, DFS, and LRFS in triple negative breast cancer patients with $\geq 4$ positive nodes. Cox regression analysis showed that post-mastectomy radiotherapy was also a significant prognostic factor. However, it did not improve survival in triple negative breast cancer patients with 1-3 positive nodes. The American Society of Clinical Oncology has recommended that patients with $\geq 4$ positive nodes undergo routine post-mastectomy radiotherapy [26]. Post-mastectomy radiotherapy is undecided for patients with 1-3 positive nodes or with T1 or T2 tumors. Our results have potential to add new knowledge for these recommendations.

Bassam et al. reported that women with T1-2/ N0 triple negative breast cancer who were treated with modified radical mastectomy without post-mastectomy radiotherapy had an increased risk of loco-regional recurrence compared to those treated with lumpectomy and adjuvant radiotherapy [26]. Decisions regarding the surgical approach for breast cancer treatment may reflect economic and cultural differences. Breast-conserving surgery is the primary surgical treatment for breast cancer worldwide. Approximately $60 \%-70 \%$ of patients with stage 0 -II breast cancer in the United States undergo breast-conserving surgery [27]. However, a multicenter retrospective study in China indicated that modified radical mastectomy is still the most common surgical approach in China for breast cancer treatment [28].

Data from the Hong Kong Breast Cancer Registry indicated that there was a lower rate of breast-conserving surgery among Chinese patients with early invasive breast cancer [29]. A retrospective study that assessed the surgical management of breast cancer at a single center in Shanghai from 1999-2013 reported that 81.7\% of the patients underwent mastectomy while only $15.2 \%$ underwent breast-conserving surgery. In addition, only $21.5 \%(606 / 2811)$ of ER-negative breast cancer patients underwent breast-conserving surgery. Only approximately $3.27 \%$ of triple negative breast cancer patients were treated with breast-conserving surgery [30]. The number of patients who underwent breast-conserving surgery was also low among T1/T2 triple negative breast cancer patients from the Heilongjiang Province in China. In our study, the prognosis of triple negative breast cancer patients who did not have lymph node metastasis and who were treated with breast-conserving surgery and post-operative radiotherapy was similar to that of patients treated with mastectomy alone. Because we had a limited number of patients who underwent breast-conserving surgery in our province, additional studies are needed to confirm our findings.

Our data suggest that post-mastectomy radiotherapy is beneficial in triple negative breast cancer patients with $\geq 4$ positive nodes, but that there is little to no advantage of radiotherapy for patients with 1-3 positive nodes. These data are important given the well-known side effects of loco-regional, post-mastectomy radiotherapy [31-33]. Our findings have clear implications for the management of triple negative breast cancer patients with $1-3$ or $\geq$ 4 positive lymph nodes. Additional studies with larger sample sizes are needed to confirm the importance of postmastectomy radiotherapy for triple negative breast cancer patients with $\geq 4$ positive lymph nodes.

\section{MATERIALS AND METHODS}

All medical records were collected with the consent of the patients. The study protocol was approved by Harbin Medical University Cancer Hospital, Harbin, China. The inclusion criteria were (1) primary, operable triple negative breast cancer with tumor size $\leq 5 \mathrm{~cm}$; and (2) clinical data available between the initial diagnosis and clinical follow-up. The exclusion criteria were (1) locally advanced disease with recurrent tumors, (2) 
treatment with neo-adjuvant chemotherapy, (3) metastatic disease, (4) tumor size $>5 \mathrm{~cm}$, (5) the presence of too few cases (number $<5$ ) which were no advantage of statistical analysis.

The primary outcome of the study was mortality from all causes. Treatment data and patient clinical features were analyzed. Treatment data included the surgical approach (mastectomy or breast-conserving surgery), chemotherapy (yes, no), and adjuvant radiotherapy (yes, no). Surgical methods included modified radical mastectomy, mastectomy with sentinel lymph node biopsy, and breast-conserving surgery. Modified radical mastectomy and mastectomy with sentinel lymph node biopsy were collectively referred to as mastectomy. Tumor characteristics included the histological tumor size (in $\mathrm{cm}$ ), number of positive lymph nodes, histological grade, Ki67 index, and P53 status.

ER, PR, and HER2 status was assessed by immunohistochemistry. We considered $>10 \%$ nuclear staining of ER and PR in the invasive component of the tumor to be positive. The intensity of the antiHER2 staining was divided into four grades from 0-3 such that 0 was negative, 1 was slightly positive, 2 was indeterminate, and 3 was positive, as described previously $[34,35]$. We re-categorized grades 0 and 1 as negative, and grade 3 was considered positive. Fluorescent in situ hybridization was performed on all grade 2 samples. Samples with a $<2$-fold change in expression were considered negative, and samples with a $>2$-fold change were considered positive for HER2 gene amplification [36]. Tumor samples with $\mathrm{Ki} 67 \geq 14 \%$ were considered highly proliferative [37].

\section{Follow-up}

All patients we analyzed were followed-up every 3-6 months for the first 5 years and every 12 months thereafter. The clinical and pathological records of all patients in the study were reviewed regularly as part of the analysis. Patients were followed for $\geq 5$ years at the Harbin Medical University Cancer Hospital or until they died. We evaluated OS, DFS, and LRFS. Survival time was defined as the period from the date of diagnosis to either the date of death or the end of the study (June 31, 2015).

\section{Statistical analysis}

All statistical analyses were performed using SPSS 17.0 for Windows. Survival curves were plotted using the Kaplan-Meier method and differences were assessed using log-rank tests. The influence of different variables on survival was assessed using the Cox univariate and multivariate regression analyses. $P$ values $<0.05$ were considered statistically significant.

\section{ACKNOWLEDGMENTS}

The authors thank all the patients who provided data and the research staff for their contributions to this project.

\section{CONFLICTS OF INTEREST}

The authors declare that there are no conflicts of interest.

\section{FUNDING}

The study was supported by research grants from the Harbin Medical University Graduate Student Innovation Fund Project, Heilongjiang Province, China (Number: YJSCX2015-31HYD).

\section{REFERENCES}

1. Ward EM, DeSantis CE, Lin CC, Kramer JL, Jemal A, Kohler B, Brawley OW, Gansler T. Cancer statistics: Breast cancer in situ. CA Cancer J Clin. 2015; 65:481-495.

2. Perou CM, Sorlie T, Eisen MB, van de Rijn M, Jeffrey SS, Rees CA, Pollack JR, Ross DT, Johnsen H, Akslen LA, Fluge O, Pergamenschikov A, Williams C, et al. Molecular portraits of human breast tumours. Nature. 2000; 406:747-752.

3. Brenton JD, Carey LA, Ahmed AA, Caldas C. Molecular classification and molecular forecasting of breast cancer: ready for clinical application? J Clin Oncol. 2005; 23:7350-7360.

4. Sotiriou C, Neo SY, McShane LM, Korn EL, Long PM, Jazaeri A, Martiat P, Fox SB, Harris AL, Liu ET. Breast cancer classification and prognosis based on gene expression profiles from a population-based study. Proc Natl Acad Sci U S A. 2003; 100:10393-10398.

5. Nielsen TO, Hsu FD, Jensen K, Cheang M, Karaca G, Hu Z, Hernandez-Boussard T, Livasy C, Cowan D, Dressler L, Akslen LA, Ragaz J, Gown AM, et al. Immunohistochemical and clinical characterization of the basal-like subtype of invasive breast carcinoma. Clin Cancer Res. 2004; 10:5367-5374.

6. Matos I, Dufloth R, Alvarenga M, Zeferino LC, Schmitt F. p63, cytokeratin 5, and P-cadherin: three molecular markers to distinguish basal phenotype in breast carcinomas. Virchows Arch. 2005; 447:688-694.

7. Lowery AJ, Kell MR, Glynn RW, Kerin MJ, Sweeney KJ. Locoregional recurrence after breast cancer surgery: a systematic review by receptor phenotype. Breast Cancer Res Treat. 2012; 133:831-841.

8. Pignol JP, Rakovitch E, Olivotto IA. Is breast conservation therapy superior to mastectomy for women with triplenegative breast cancers? J Clin Oncol. 2011; 29:2841-2843. 
9. Clarke M, Collins R, Darby S, Davies C, Elphinstone P, Evans V, Godwin J, Gray R, Hicks C, James S, MacKinnon E, McGale P, McHugh T, et al. Effects of radiotherapy and of differences in the extent of surgery for early breast cancer on local recurrence and 15-year survival: an overview of the randomised trials. Lancet. 2005; 366:2087-2106.

10. McGale P, Taylor C, Correa C, Cutter D, Duane F, Ewertz M, Gray R, Mannu G, Peto R, Whelan T, Wang Y, Wang Z, Darby S. Effect of radiotherapy after mastectomy and axillary surgery on 10-year recurrence and 20-year breast cancer mortality: meta-analysis of individual patient data for 8135 women in 22 randomised trials. Lancet. 2014; $383: 2127-2135$

11. Darby S, McGale P, Correa C, Taylor C, Arriagada R, Clarke M, Cutter D, Davies C, Ewertz M, Godwin J, Gray R, Pierce L, Whelan T, et al. Effect of radiotherapy after breast-conserving surgery on 10-year recurrence and 15-year breast cancer death: meta-analysis of individual patient data for 10,801 women in 17 randomised trials. Lancet. 2011; 378:1707-1716.

12. Abdulkarim BS, Cuartero J, Hanson J, Deschenes J, Lesniak D, Sabri S. Increased risk of locoregional recurrence for women with T1-2N0 triple-negative breast cancer treated with modified radical mastectomy without adjuvant radiation therapy compared with breast-conserving therapy. J Clin Oncol. 2011; 29:2852-2858.

13. Ragaz J, Olivotto IA, Spinelli JJ, Phillips N, Jackson SM, Wilson KS, Knowling MA, Coppin CM, Weir L, Gelmon K, Le N, Durand R, Coldman AJ, Manji M. Locoregional radiation therapy in patients with high-risk breast cancer receiving adjuvant chemotherapy: 20-year results of the British Columbia randomized trial. J Natl Cancer Inst. 2005; 97:116-126.

14. Overgaard M, Hansen PS, Overgaard J, Rose C, Andersson M, Bach F, Kjaer M, Gadeberg CC, Mouridsen HT, Jensen $\mathrm{MB}$, Zedeler K. Postoperative radiotherapy in high-risk premenopausal women with breast cancer who receive adjuvant chemotherapy. Danish Breast Cancer Cooperative Group 82b Trial. N Engl J Med. 1997; 337:949-955.

15. Overgaard M, Jensen MB, Overgaard J, Hansen PS, Rose C, Andersson M, Kamby C, Kjaer M, Gadeberg CC, Rasmussen BB, Blichert-Toft M, Mouridsen HT. Postoperative radiotherapy in high-risk postmenopausal breast-cancer patients given adjuvant tamoxifen: Danish Breast Cancer Cooperative Group DBCG 82c randomised trial. Lancet. 1999; 353:1641-1648.

16. McBride A, Allen P, Woodward W, Kim M, Kuerer HM, Drinka EK, Sahin A, Strom EA, Buzdar A, Valero V, Hortobagyi GN, Hunt KK, Buchholz TA. Locoregional recurrence risk for patients with T1,2 breast cancer with 1-3 positive lymph nodes treated with mastectomy and systemic treatment. Int J Radiat Oncol Biol Phys. 2014; 89:392-398.

17. Goldhirsch A, Winer EP, Coates AS, Gelber RD, PiccartGebhart M, Thurlimann B, Senn HJ. Personalizing the treatment of women with early breast cancer: highlights of the St Gallen International Expert Consensus on the Primary Therapy of Early Breast Cancer 2013. Ann Oncol. 2013; 24:2206-2223.

18. Wang J, Shi M, Ling R, Xia Y, Luo S, Fu X, Xiao F, Li J, Long X, Hou Z, Chen Y, Zhou B, Xu M. Adjuvant chemotherapy and radiotherapy in triple-negative breast carcinoma: a prospective randomized controlled multicenter trial. Radiother Oncol. 2011; 100:200-204.

19. Parker CC, Ampil F, Burton G, Li BD, Chu QD. Is breast conservation therapy a viable option for patients with triple-receptor negative breast cancer? Surgery. 2010; 148:386-391.

20. Adkins FC, Gonzalez-Angulo AM, Lei X, HernandezAya LF, Mittendorf EA, Litton JK, Wagner J, Hunt KK, Woodward WA, Meric-Bernstam F. Triple-negative breast cancer is not a contraindication for breast conservation. Ann Surg Oncol. 2011; 18:3164-3173.

21. Zumsteg ZS, Morrow M, Arnold B, Zheng J, Zhang Z, Robson M, Traina T, McCormick B, Powell S, Ho AY. Breast-conserving therapy achieves locoregional outcomes comparable to mastectomy in women with T1-2N0 triple-negative breast cancer. Ann Surg Oncol. 2013; 20:3469-3476.

22. Steward LT, Gao F, Taylor MA, Margenthaler JA. Impact of radiation therapy on survival in patients with triple-negative breast cancer. Oncol Lett. 2014; 7:548-552.

23. Dent R, Trudeau M, Pritchard KI, Hanna WM, Kahn HK, Sawka CA, Lickley LA, Rawlinson E, Sun P, Narod SA. Triple-negative breast cancer: clinical features and patterns of recurrence. Clin Cancer Res. 2007; 13:4429-4434.

24. Kyndi M, Sorensen FB, Knudsen H, Overgaard M, Nielsen HM, Overgaard J. Estrogen receptor, progesterone receptor, HER-2, and response to postmastectomy radiotherapy in high-risk breast cancer: the Danish Breast Cancer Cooperative Group. J Clin Oncol. 2008; 26:1419-1426.

25. Nordenskjold AE, Fohlin H, Albertsson P, Arnesson LG, Chamalidou C, Einbeigi Z, Holmberg E, Nordenskjold B, Karlsson P. No clear effect of postoperative radiotherapy on survival of breast cancer patients with one to three positive nodes: a population-based study. Ann Oncol. 2015; 26:1149-1154.

26. Recht A, Edge SB, Solin LJ, Robinson DS, Estabrook A, Fine RE, Fleming GF, Formenti S, Hudis C, Kirshner JJ, Krause DA, Kuske RR, Langer AS, et al. Postmastectomy radiotherapy: clinical practice guidelines of the American Society of Clinical Oncology. J Clin Oncol. 2001; 19:1539-1569.

27. McGuire KP, Santillan AA, Kaur P, Meade T, Parbhoo J, Mathias M, Shamehdi C, Davis M, Ramos D, Cox CE. Are mastectomies on the rise? A 13-year trend analysis of the selection of mastectomy versus breast conservation therapy in 5865 patients. Ann Surg Oncol. 2009; 16:2682-2690. 
28. Zhang B, Song Q, Tang Z, Xie X, Yang H, He J, Li H, Li J, Fan J, Huang R, Zhang H, Qiao Y. A 10-year (1999 2008) retrospective multi-center study of breast cancer surgical management in various geographic areas of China. Breast. 2013; 22:676-681.

29. Chan SW, Cheung C, Chan A, Cheung PS. Surgical options for Chinese patients with early invasive breast cancer: Data from the Hong Kong Breast Cancer Registry. Asian J Surg. 2016. doi: 10.1016/j.asjsur.2016.02.003.

30. Huang NS, Liu MY, Chen JJ, Yang BL, Xue JY, Quan CL, Mo M, Liu GY, Shen ZZ, Shao ZM, Wu J. Surgical management of breast cancer in China: A 15-year singlecenter retrospective study of 18,502 patients. Medicine (Baltimore). 2016; 95:e4201.

31. Shields HM, Recht A, Wang HH. Exposure to both radiation and chemotherapy increases the risk of Barrett's and multilayered epithelium. Dig Dis Sci. 2009; 54:2143-2149.

32. Recht L, Fram RJ, Strauss G, Fitzgerald TJ, Liepman M, Lew R, Kadish S, Sherman D, Wilson J, Greenberger J, Egan PD, Silver D. Preirradiation chemotherapy of supratentorial malignant primary brain tumors with intracarotid cis-platinum (CDDP) and i.v. BCNU. A phase II trial. Am J Clin Oncol. 1990; 13:125-131.
33. Lingos TI, Recht A, Vicini F, Abner A, Silver B, Harris JR. Radiation pneumonitis in breast cancer patients treated with conservative surgery and radiation therapy. Int J Radiat Oncol Biol Phys. 1991; 21:355-360.

34. Hsu CY, Ho DM, Yang CF, Lai CR, Yu IT, Chiang H. Interobserver reproducibility of $\mathrm{Her}-2 / \mathrm{neu}$ protein overexpression in invasive breast carcinoma using the DAKO HercepTest. American journal of clinical pathology. 2002; 118:693-698.

35. Yeoh G, Barton S, Kaestner K. The International Journal of Biochemistry \& Cell Biology. Preface. Int J Biochem Cell Biol. 2011; 43:172.

36. Aksoy S, Dizdar O, Harputluoglu H, Altundag K. Demographic, clinical, and pathological characteristics of Turkish triple-negative breast cancer patients: single center experience. Annals of oncology. 2007; 18:1904-1906.

37. Cheang MC, Chia SK, Voduc D, Gao D, Leung S, Snider J, Watson M, Davies S, Bernard PS, Parker JS, Perou CM, Ellis MJ, Nielsen TO. Ki67 index, HER2 status, and prognosis of patients with luminal B breast cancer. Journal of the National Cancer Institute. 2009; 101:736-750. 